\title{
Armoni Araması Yöntemi ile Elektrik Dağıtım Sistemlerinin Yeniden Yapılandırılması: Elektrikli Araçların Etkisi
}

\author{
Oğuzhan CEYLAN* \\ Kadir Has Üniversitesi, Yönetim Bilişim Sistemleri Bölümü, İstanbul \\ (ORCID: 0000-0002-0892-6380)
}

\begin{abstract}
$\ddot{O} \mathbf{z}$
Bilindiği üzere son yirmi yılda elektrik güç sistemleri yoğun değişimler yaşamıştır. Elektrik piyasalarının yapısı değişmiş, tüm dünyada elektrik dağıtım sistemlerinde yenilenebilir enerji kaynaklarının ve elektrikli araçların $(E A)$

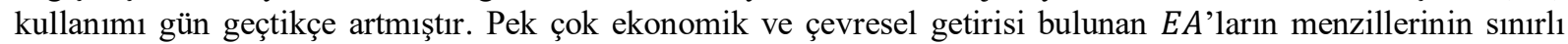
olması, neredeyse her gün şarj edilmelerini gerektirmekte ve bu da elektrik güç sistemine ek yük getirmektedir. Bu çalışmada elektrik dağıtım sistemlerinde çok sayıda $E A$ olması durumunda karşılaşılan gerilim problemleri ve kayıpları minimize etmek için yeniden yapılandırma yaklaşımı incelenmektedir. Eniyileme probleminin çözümü için armoni araması yöntemi $(A A Y)$ kullanılmaktadır. Ortaya konan yaklaşımla, sistemde farklı sayıda $E A$ ve dağıtık generatör olması durumları dikkate alınarak IEEE 33 bara test sisteminde çözülmekte ve ardından sonuçlara yer verilmektedir.
\end{abstract}

Anahtar kelimeler: Elektrik dağıtım sistemleri, yeniden yapılandırma, eniyileme, armoni araması yöntemi.

\section{Reconfiguration of Electrical Distribution Systems by Harmony Search Method: Impact of Electrical Vehicles}

\begin{abstract}
As known power systems have faced dramatic changes for two decades. The structure of the electricity markets have changed, the usage levels of renewable energy sources and electrical vehicles $(E V)$ increased more day by day in power distribution systems. This study deals with encountered problems of distribution systems with large number of $E V$ s. $E V$ s have several advantages in terms of environmental and economical facts however generally their driving range is limited, hence they have to be recharged nearly every day and this brings additional load to the system. This study aims at solving voltage problems and power loss problems in distribution systems in the existence of large number of electrical vehicles. Optimization problem is solved by harmony search $(H S)$ algorithm. Proposed approach is tested on IEEE 33 bus test system with distributed generators and results are presented.
\end{abstract}

Keywords: power distribution systems, reconfiguration, optimization, harmony search method.

\section{Giriş}

Elektrik güç sistemleri son yıllarda büyük değişimlerden geçmektedir. İlk akla gelenleri, elektrik idaresinin dikey yapıdan yatay yapıya geçmesi ve özellikle dağıtım sistemlerinin özelleşmesidir. Dünyadaki bu eğilime ülkemiz de ayak uydurmuştur. Ayrıca, özellikle, bilişim teknolojilerinin, elektronik teknolojilerinin hızlı ilerleyişi, bu teknolojilerin elektrik güç sistemlerinde daha sık kullanılmasına sebep olmuştur. Bu yoğunluk nedeniyle karmaşıklaşan sistemin daha "akıllı" bir şekilde işletilmesi zarureti doğmuş ve "akıllı şebeke" kavramı ortaya çıkmıştır.

\footnotetext{
*Sorumlu yazar: oguzhan.ceylan@khas.edu.tr 
Fosil kökenli kaynakların yüksek maliyeti ve zararları ile diğer çevresel kaygıların etkisiyle yenilenebilir enerji kaynaklarının elektrik güç sistemlerinde kullanımı hızla artmıştır. $E A$ gelişimi ve kullanımı da benzer bir seyir izlemiştir. Uluslararası Enerji Ajansı'nın güncel bir raporuna [1] göre 2016 yılında dünya çapında toplam 750 bin $E A$ satılmışıı. Gene aynı rapora göre, $E A$ satış1 ve kullanımı önümüzdeki yıllarda daha da artacaktır. $E A^{\prime}$ ların ortalama menzilleri pek fazla değildir. Sözgelimi Nissan Leaf' in güncel menzili yaklaşık 171 kilometredir (106 mil) [2]. ABD'de yapılan bir araştırmaya [3] göre 2001 yılında günlük ortalama araba kullanımı yaklaşık 53 kilometredir (33 mil). Bir EA sahibinin aracını işe gidip gelmek için kullanacağı düşünüldüğünde, İstanbul gibi büyükşehirlerde günde ortalama $70 \mathrm{~km}$ yol gideceği varsayılabilir. Bu da $E A^{\prime}$ ların gidilen yola göre her gün ya da iki günde bir şarj edilmesini gerektirir.

Elektrik dağıtım sistemleri radyal yapıdaki sistemlerdir. Bu tip sistemlerde gerilim, hat sonundaki düğ̈̈m noktasına doğru gittikçe (sistemdeki yüklerden ötürü) düşer. Sistem gerilimi, kademe ayarlı transformatörlerle ve kapasitörlerle kontrol edilebilir [4]. Son zamanlarda geliştirilen inverter teknolojisi de gerilim kontrolünde kullanılabilir [4,5]. Elektrik dağıtım sistemlerinde karşılaşılan gerilim kontrolü probleminin ve sistem kayıplarının fazla olması probleminin üstesinden gelmenin bir yolu da yeniden yapılandırma olarak adlandırılan sistem topolojisini anahtarlarla değiştirmektir. Literatürde bu konuda çok fazla çalışma yapılmıştır. Bunlardan ilki, Merlin ve arkadaşlarının çalışmasıdır [6]. Problem, karışık tamsayı programlama ile modellenerek çözülmüştür. Sonraki yıllarda da benzer çalışmalarla yeni modeller önerilmiştir [7-17].

Bilindiği üzere, eniyileme problemleri, analitik ya da sayısal yöntemler kullanarak çözülebilir [18]. Ancak, elektrik güç sistemlerinin karmaşıklığı, sayısal yöntemlerin daha sık kullanılmasına neden olmuştur. Sayısal yöntemler, "türev tabanlı olanlar" ve "türev tabanlı olmayanlar" olarak sinıflandırılabilirler. Türev tabanlı yöntemler kullanıldığında yakınsama sorunuyla karşılaşılabilmektedir. Bunun da etkisiyle türev tabanlı olmayan popülasyon tabanlı veya doğa esinli yöntemlere son zamanlarda sıkça başvurulmaktadır. Bu yöntemler ilk başta belirli bir arama uzayında rastgele çözüm adayları oluştururlar. Sonraki aşamalarda, (doğadaki olguları da kullanarak) önceki çözüm adaylarının kombinasyonları ya da arama uzayındaki rastgele üretilen değerler belirli olasılıklarla kullanılır ve böylece yeni çözüm adayları oluşturulur. Üretilen yeni çözüm adaylarının eski çözüm adaylarının en kötüleri ile kıyaslanması sonucu daha iyi çözüm adaylarına ulaşılır. Elektrik dağııım sistemlerinde yeniden yapılandırma probleminde de ilk kez popülasyon tabanlı yöntemlerden genetik algoritmalar [10] kullanılmıştır. Parçacık sürüsü eniyilemesi [11], tabu araması yöntemi [12-13], karınca kolonisi algoritmas1 [14], ateşböceği algoritmas1 [15], guguk kuşu algoritmas1 [16] daha sonra kullanılan akıllı yöntem tabanlı yaklaşımlara örnek olarak verilebilir. Benzer şekilde, $A A Y$ [17] ile de probleme çözüm aranmıştır.

Bu çalışmada, 2001 yılında caz müziğinden etkilenilerek geliştirilen bir yöntem olan $A A Y$ kullanılarak elektrik dağıtım sisteminde yeniden yapılandırma problemi çözülecektir. Sistemde farklı sayıda $E A$ ve dağıtık generatör bulunduğu varsayılmaktadır. Yakın gelecekte dağıtım sistemlerinde çok sayıda $E A$ ve dolayısıyla gerilim sorununun bulunacağı düşünülmektedir. İşte bu çalışmaya da sorunların giderilmesi ve kayıpların azaltılması amacı yön vermektedir. Ayrıca bazı $E A$ 'lar dağııım sisteminde şarj olurken, diğerlerinin yollarda bulunacağı açıktır. $\mathrm{Bu}$ sebeple, çalışmada farklı durumların benzetimleri yapılacak ve farklı yük durumları için sonuçlar üretilecektir.

Çalışmanın bir sonraki bölümünde ortaya konan elektrik dağıtım sistemi eniyileme modeline yer verilecektir. Ayrıca $A A Y$ ile eniyileme probleminin çözülüş biçimi ve $A A Y$ 'nin yeniden yapılandırma probleminde uygulanmasına değinilecektir. IEEE 33 Düğüm test sistemlerinde farklı sayıda $E A$ ve dağıtık generatörün bulunduğu durumlar için benzetim sonuçları verilecek ve yorumlanacaktır.

\section{Model}

Elektrik dağıtım sistemlerinde gün içinde yükler sabit değildir ve sürekli değişmektedir. Öte yandan çok sayıda $E A$ 'nın varlığı sisteme ek bir yük getirecektir. Yeniden yapılandırma probleminde amaç fonksiyonu, sistemdeki kayıpların azaltılması ve gerilim sapmasının azaltılması olacaktır. Amaç fonksiyonu aşağıdaki gibidir:

$$
F=\text { Hat kayıplar } \iota+\text { gerilim sapması }
$$


$F=\left(\sum_{i=1}^{N h a t} R_{i} I_{i}^{2}\right)+k\left(V_{i}-1\right)^{2}$

Burada $R_{i}$ sistemdeki her hattaki direnci, $I_{i}$ sistemdeki her hattaki akımı, $V_{i}$ sistemdeki dügüm gerilimlerini göstermektedir. Hat kayıplarının mertebesi ile gerilimin 1 per unit değerinden sapmasının mertebesinin aynı seviyede olmaması nedeniyle gerilim sapmasının başına bir $k$ katsayısı eklenmiştir. Eniyileme kısıtı olarak sistemin radyal yapısının bozulmaması göz önüne alınmıştır:

Radyal $=1$

Burada (3) ifadesi, sistemin radyal yapısının korunmasının bir kısıt olarak eniyileme problemine eklendiğini gösterir.

\section{Armoni Araması Yöntemi}

$A A Y 2001$ yılında Geem ve arkadaşları tarafından geliştirilen [19, 20] popülasyon tabanlı bir eniyileme yöntemidir. Yöntem, caz müzisyenlerinin daha iyi bir ezgi bulabilmek için yaptıkları doğaçlamanın benzetimine dayalıdır. Popülasyon tabanlı yöntemlerin ilk akla geleni doğada güçlü olanın hayatta kalabilmesi ilkesine dayanan genetik algoritmalardır [21,22]. Sonraki yıllarda, doğadaki kuş sürülerinin yiyecek arama davranışlarını modelleyen parçacık sürüsü eniyilemesi [23], karıncaların yemek ararken salgıladıkları feromen salgısına göre yön bulmalarını temel alan karınca sürüsü eniyilemesi [24] gibi yöntemler de ortaya konulmuştur. Çalışmada $A A Y^{\prime}$ 'nin seçilme sebebi, yöntemin hızlı bir şekilde en iyi çözüme yakın çözümleri elde edebilme yeteneğidir [25].

$\boldsymbol{A} \boldsymbol{A} \boldsymbol{Y}$ ile eniyileme probleminin çözümüne başlamadan önce Armoni Arama Boyutu $(\boldsymbol{A} \boldsymbol{A B})$, armoni hafizası değerlendirme oranı $(\boldsymbol{A H D O})$ ve perde ayarlama değeri $(\boldsymbol{P} \boldsymbol{A D})$ belirlenir. Genelde, $\boldsymbol{A} \boldsymbol{A B}$ değişken sayısının 10-15 katı arasında bir değer olarak saptanır. Öte yandan $\boldsymbol{A H D O}$ ve $\boldsymbol{P} \boldsymbol{A D}$ yöntemin davranışını belirleyen iki temel parametredir. AHDO parametresi kullanılarak, yeni elde edilecek çözüm adaylarının ne kadarının eski çözüm adaylarından ya da armoni hafızasından $(\boldsymbol{A H})$ ve ne kadarının arama uzayı içerisinden rastgele seçileceği belirlenir. Üretilen her yeni çözüm adayının belirli bir olasılıkla, belirlenen bant genişliği $(\boldsymbol{B G})$ oranında bulunduğu konumdan saptırılması $\boldsymbol{P} \boldsymbol{A D}$ 'a bağlıdır. Belirtilmelidir ki, aşağıda ayrıntılı biçimde anlatılan $\boldsymbol{A A Y}$ yönteminde oluşturulan tüm rastgele sayılar 0 ile 1 arasında oluşturulmaktadır. AHDO genelde 0.7-0.9 arasında bir değer olarak belirlenir. $\boldsymbol{P} \boldsymbol{A D}$ değerinin 0.05 ile 0.3 arasında belirlenmesi sıkça gözlemlenir [19, 20, 25].

\section{1. İlk Çözüm Adaylarının Oluşturulması}

$A A Y$ ile bir eniyileme probleminin çözümünde, ilk olarak daha önceden belirlenmiş bir arama uzayı içinde $A H$ kadar, boyutu $A A B$ olacak kadar rastgele çözüm adayları oluşturulur. En küçük değeri bulunması istenen fonksiyon aşağıda gibi olsun:

Enküçükle $F\left(x_{1}, x_{2}, \cdots, x_{n}\right)$

Bu fonksiyon için arama uzayı $x_{i}^{\text {enküçük }} \leq x_{i} \leq x_{i}^{\text {enbüyük }}$ olacaktır. Burada $x_{i}^{\text {enküçük }}, x_{i}$ ve $x_{i}^{\text {enbüyük }}$ sırasıyla, bir değişkenin alabileceği en küçük değeri, bir değişkenin değerini ve bir değişkenin alabileceği en büyük değeri göstermektedir. Buna göre $A A B \mathrm{~m}$ ise, rastgele $\mathrm{m}$ adet çözüm adayı belirtilen değerler arasında aşağıdaki gibi oluşturulur ve (5)'de gösterildiği gibi $A H$ matrisinde saklanır.

$A H=\left[\begin{array}{cccc}x_{1}^{1} & x_{2}^{1} & \cdots & x_{n}^{1} \\ x_{1}^{2} & x_{2}^{2} & \cdots & x_{n}^{2} \\ \vdots & \vdots & \vdots & \vdots \\ x_{1}^{m} & x_{2}^{m} & \cdots & x_{n}^{m}\end{array}\right]$

$A H$ matrisinin her satırı, en küçükleştirilecek fonksiyonda yerine konularak fonksiyon değeri hesaplanır. Sona, doğaçlama aşaması gündeme gelir. Bu aşama hafiza değerlendirmesi, perde 
ayarlaması ve rastgele üretim aşamalarından oluşur. Doğaçlama aşamasındaki işlemler aşağıda anlatılmaktadir.

\subsection{Doğaçlama}

Bu aşamada $A H$ kullanılarak yeni bir çözüm adayı oluşturulur. Yeni çözüm adayı (ÇA) aşağıdaki gibi gösterilirse:

$\mathrm{C} A=\left[\begin{array}{llll}x_{1}^{\text {yeni }} & x_{2}^{\text {yeni }} & \ldots & x_{n}^{\text {yeni }}\end{array}\right]$

ÇA'nın elemanları $A H D O$ 'ya göre belirlenir. Aşağıda verilen olasılıklarla ÇA'nın her yeni elemanı ya $A H^{\prime}$ 'den seçilir ya da arama uzayı içinden (7) ifadesinde gösterildiği gibi rastgele oluşturulur:

$x_{i}^{\text {yeni }}=\left\{\begin{array}{c}x_{i}^{\text {yeni }} \in\left\{x_{i}^{1}, x_{i}^{2}, \cdots, x_{i}^{m}\right\}, \text { rastgele sayı }<\text { AHDO ise } \\ x_{i}^{\text {enküçük }} \leq x_{i}^{\text {yeni }} \leq x_{i}^{\text {enbüyük }}, \text { rastgele sayı }>\text { AHDO ise }\end{array}\right.$

Oluşturulan yeni çözüm adayı $P A D$ 'a göre bir miktar azaltılıp, arttırılabilir. Bu işlem genetik algoritmalardaki mutasyon işleminin muadili olarak düşünülebilir ve perde ayarlaması olarak adlandırılır. Oluşturulan rastgele sayıya göre işlem aşaması aşağıdaki gibi gösterilebilir:

$x_{i}^{\text {yeni }}$ için perde ayarlama kararl $\leftarrow\left\{\begin{array}{c}\text { evet, rastgele sayı }<P A D \text { ise } \\ \text { hayır, rastgele sayı }>P A D \text { ise }\end{array}\right.$

Buna göre eğer perde ayarlama kararı olumlu ise, oluşturulmuş olan yeni çözüm adayı aşağıda gösterilen biçimde değiştirilecektir:

$x_{i}^{\text {yeni }}=x_{i}^{\text {yeni }} \mp B G *$ rastgele sayı

\section{3. $A H$ 'nin Değiştirilmesi}

Bu aşamada elde edilen yeni çözüm adayı, $A H$ içindeki en kötü çözüm adayı ile karşılaştırılır. Eğer yeni çözüm adayı daha iyi amaç fonksiyonu üretiyorsa, $A H$ içindeki en kötü amaç fonksiyonu üreten çözüm adayının yerini alır.

\subsection{Durma Koşulunun Sınanması}

Önceden belirlenen bir durma koşulu sağlanıncaya kadar doğaçlama ve $A H$ 'nin değiştirilmesi işlemi yinelenir. Durma koşulu olarak belirli bir sayıda yineleme sayısı seçilebilir. Bir adımda elde edilen en iyi çözüm değeri belirli bir yineleme adımı boyunca değişmiyor ya da çok az değişiyorsa bu da bir durma koşulu olarak belirlenebilir.

\section{Armoni Araması Yönteminin Elektrik Dağıtım Sistemi Yeniden Yapılandırma Probleminde Uygulanması}

$A A Y$ ile çözüme başlamadan önce sistem radyal yapısının bozulmamasının sınanması gerekir; bunun için bu çalışmada [11]'de verilen aşağıdaki yaklaşım kullanılır.

\subsection{Radyal Yapının Korunması}

Yeniden yapılandırma probleminde radyal yapı bozulmadan anahtarlama noktaları bulunacak ve açık hatlar belirlenecektir. Örnek bir sistem olarak aşağıdaki şekilde devre yapısı verilen 33 düğüm noktalı sistem incelensin. 


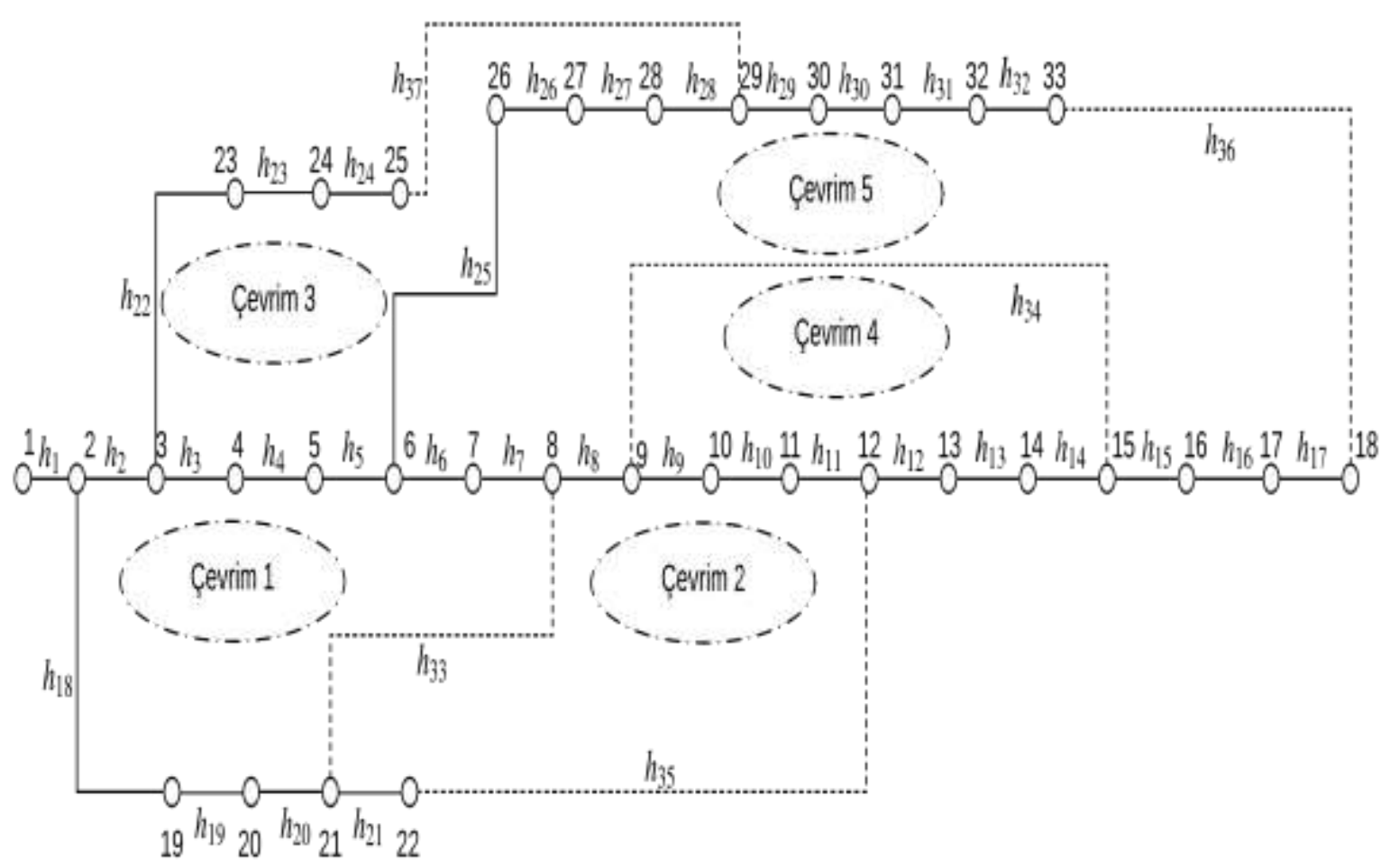

Şekil 1. 33 düğüm noktalı dağıtım sistemi

Çözüme başlamadan önce sistemdeki düğüm sayısı $D$ ve hat sayısı $H$ ise $H-D$ adet açık hat belirlenmesi gerekir. Şekil 1'deki dağıtım sisteminde 5 adet açık hat bulunmaktadır. Buna göre çözüm adayı sayısı 5 olacaktır.

Normal yaklaşımda tüm hatlar çözüm adayları olarak belirlenebilir. Ancak, bu arama uzayının büyümesine ve hesaplama süresinin uzamasına neden olur. Dolayısıyla, [11]'deki yaklaşım bu çalışmada referans alınmaktadır. Buna göre çözüme başlamadan önce sistemdeki çevrimler ve bu çevrimlere ait hatlar elde edilir; ayrı ayrı vektörlerde tutulur ve bunlar Çevrim Vektörleri $(C ̧ V)$ olarak adlandırılır. Örneğin yukarıda verilen 33 düğüm noktalı sistem için ÇV aşağıda verilmektedir.

$$
\begin{aligned}
& C V_{1}=\left[\begin{array}{llllllllll}
h_{2} & h_{3} & h_{4} & h_{5} & h_{6} & h_{7} & h_{18} & h_{19} & h_{20} & h_{33}
\end{array}\right] \\
& C V_{2}=\left[\begin{array}{llllll}
h_{8} & h_{9} & h_{10} & h_{11} & h_{33} & h_{35}
\end{array}\right] \\
& C_{C} V_{3}=\left[\begin{array}{lllllllllll}
h_{3} & h_{4} & h_{5} & h_{22} & h_{23} & h_{24} & h_{25} & h_{26} & h_{27} & h_{28} & h_{37}
\end{array}\right] \\
& C V_{4}=\left[\begin{array}{lllllll}
h_{9} & h_{10} & h_{11} & h_{12} & h_{13} & h_{14} & h_{34}
\end{array}\right] \\
& \boldsymbol{C} V_{5}=\left[\begin{array}{llllllllllll}
h_{6} & h_{7} & h_{8} & h_{15} & h_{16} & h_{17} & h_{25} & h_{26} & h_{27} & h_{28} & h_{29} & h_{30}
\end{array}\right. \\
& \left.\begin{array}{lllll}
h_{31} & h_{32} & h_{33} & h_{34} & h_{36}
\end{array}\right]
\end{aligned}
$$

Sonra elde edilen çevrim vektörleri arasında ortak hatlardan oluşan Ortak Hatlar Vektörleri $(\mathrm{OHV})$ bulunur. Gene aynı sistem için bunlar aşağıda yer almaktadır:

$$
\begin{aligned}
& O H V_{12}=C V_{1} \cap C V_{2}=\left[h_{33}\right] \\
& O H V_{13}=C C V_{1} \cap C V_{3}=\left[\begin{array}{lll}
h_{3} & h_{4} & h h_{5}
\end{array}\right] \\
& O H V_{14}=C, V_{1} \cap C V_{4}=[] \\
& O H V_{15}=C V_{1} \cap C V_{5}=\left[\begin{array}{ll}
h_{6} & h_{7}
\end{array}\right] \\
& O H V_{23}=C_{2} V_{2} \cap C V_{3}=[] \\
& O H V_{24}=C V_{2} \cap C V_{4}=\left[\begin{array}{lll}
h_{9} & h_{10} & h_{11}
\end{array}\right] \\
& O H V_{25}=C V_{2} \cap C V_{5}=\left[h_{8}\right]
\end{aligned}
$$




$$
\begin{aligned}
& O H V_{34}=C \zeta V_{3} \cap C \zeta V_{4}=[] \\
& O H V_{35}=C C V_{3} \cap C \zeta V_{5}=\left[\begin{array}{llll}
h_{25} & h_{26} & h_{27} & h_{28}
\end{array}\right] \\
& O H V_{45}=C ̧ V_{4} \cap C \zeta V_{5}=\left[\begin{array}{lll}
h_{34}
\end{array}\right]
\end{aligned}
$$

Elde edilen bilgiler kullanılarak, bağımsız ada oluşturacağı için kullanılamayacak düğüm bilgisini içeren vektörler oluşturulur ve Engellenmiş Vektörler $(E G V)$ olarak adlandırılır. Bunlar birden fazla $O H V$ 'nin kesişimi olarak ortaya çıkmaktadır. 33 düğüm noktalı sistemde bu vektörler ve ada oluşmasına neden oldukları dügüm noktaları aşağıda gösterilmektedir:

$$
\begin{aligned}
& E G V_{125}=O H V_{12} \cap O H V_{25} \cap O H V_{15}=[8] \\
& E G V_{135}=O H V_{13} \cap O H V_{15} \cap O H V_{35}=[6] \\
& E G V_{245}=O H V_{25} \cap O H V_{45} \cap O H V_{24}=[9] \\
& E G V_{1235}=O H V_{12} \cap O H V_{13} \cap O H V_{25} \cap O H V_{35}=\left[\begin{array}{ll}
6 & 8
\end{array}\right] \\
& E G V_{1245}=O H V_{12} \cap O H V_{45} \cap O H V_{15} \cap O H V_{24}=[9] \\
& E G V_{12345}=O H V_{12} \cap O H V_{13} \cap O H V_{35} \cap O H V_{15} \cap O H V_{24}=\left[\begin{array}{lll}
6 & 8 & 9
\end{array}\right]
\end{aligned}
$$

Yukarıda verilen bilgiler ışığında, bir çözüm adayı için aşağıda belirtilen 3 kural ortaya konmuştur:

1) Çözüm adayı oluşturulurken seçilen i. hat, $C V_{i}$ 'de olmalıdır.

2) Bir $O H V$ 'den sadece bir hat seçilebilir.

3) EGV'deki, $O H V^{\prime}$ ler aynı anda bir çözüm adayı içinde bulunamaz.

Örnek olarak yukarıdaki dağıtım sisteminde bir çözüm adayı (ÇA) aşağıdaki gibi olsun:

$\mathrm{C} A=\left[\begin{array}{lllll}h_{2} & h_{22} & h_{23} & h_{13} & h_{32}\end{array}\right]$

$\mathrm{Bu} C ̧ A$ radyal yapıyı korumadığı için geçerli bir çözüm adayı olarak ortaya çıkmayacaktır. Nedeni de $h_{22}$ hattının $C ̧ V_{2}$ elemanı olmamasıdır; yani yukarıda belirtilen 1 . Kural ihlal edilmiş olacaktır. Bir başka ÇA aşağıda verilen gibi ise:

ÇA $A=\left[\begin{array}{lllll}h_{2} & h_{21} & h_{26} & h_{14} & h_{28}\end{array}\right]$

$\mathrm{Bu}$ ÇA da radyal yapıyı korumadığı için geçerli bir çözüm adayı olmayacaktır. Kolaylıkla görülebileceği gibi $h_{26}$ ve $h_{28}$ hatlarının $O H V_{35}$ içindedir. Dolayısıyla yukarıda belirtilen 2. Kural ihlal edilmiş olacaktır. 3. Kuralı ihlal eden bir ÇA aşağıda verilmektedir:

$\mathrm{C} A=\left[\begin{array}{lllll}h_{3} & h_{21} & h_{28} & h_{14} & h_{7}\end{array}\right]$

Burada $h_{3}, h_{7}$ ve $h_{28}$ sirasiyla, $O H V_{13}, O H V_{15}$ ve $O H V_{35}$ 'in elemanlarıdır. Bunlar da $E G V_{135}$ 'i oluşturdukları için bu çözüm adayı da geçerli olmayacaktır. Aşağıdaki ÇA incelenirse:

$\mathrm{C} A=\left[\begin{array}{lllll}h_{2} & h_{21} & h_{22} & h_{12} & h_{32}\end{array}\right]$

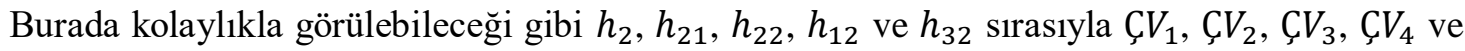
$C ̧ V_{5}$ elemanlarıdır. Yukarıda belirtilen hiçbir kural ihlal edilmediği için bu ÇA geçerli bir çözüm adayı olur.

\subsection{Armoni Araması Yöntemi ile Problemin Çözülmesi}

Yeniden yapılandırma probleminin çözümü için ilk olarak dağıtım sistemi bilgileri kullanılarak ÇV'ler oluşturulur. Ayrıca $A A B, A H D O$ ve $P A D$ parametre değerleri belirlenir, maksimum yineleme sayısına karar verilir.

Daha sonra yukarıda verilen kuralları ihlal etmeyecek şekilde, $A A B$ kadar ÇA, sistemde belirlenen ÇV'ler kullanılarak bu değerlerden rastgele oluşturulur ve böylece $A H$ elde edilir. ÇA'ların 
oluşturduğu yapılandırmalar Matpower yazılımı kullanılarak gerçeklenir ve bu yeni durumlar için yük akışı analizi koşturulur. Bilindiği üzere, yük akışı, sistem yapısı ve sistemdeki bileşenlerin aldıkları değerlere bağlı olarak her zaman yakınsamaz. Yakınsamayan durumlar için ÇA'lar göz ardı edilerek, yeni ÇA değerleri oluşturulur. Yük akışı analizi koşturulduktan sonra, sistemdeki toplam kayıp değerleri ve sistem düğüm gerilim büyüklükleri saklanır. Her bir Ç $A$ için amaç fonksiyonu değeri bulunur.

Doğaçlama aşamasında yeni bir ÇA oluşturulur. Tüm ÇA elemanları için teker teker oluşturulan rastgele sayılara bakılır. Bunlar $A H D O$ 'dan küçükse ÇA'nın ilgili elemanı rastgele bir şekilde daha önceki ÇA'lar içinden seçilir. Aksi durumda ÇA'nın ilgili elemanı ilgili ÇV'den rastgele seçilir. $\mathrm{Bu}$ aşamada oluşturulan yeni ÇA'nın yukarıda belirtilen kuralları ihlal edip etmediği kontrol edilir. Kurallar ihlal edilmiyorsa süreç devam eder, aksi durumda yeni bir ÇA, en baştan oluşturulur.

Doğaçlama, yeni ÇA'nın $P A D$ 'a göre değiştirilip değiştirilmeyeceğine karar verilmesiyle devam eder. Buna göre, oluşturulan bir rastgele sayı $P A D$ 'dan küçükse, ÇA'nın ilgili elemanı, ÇV'deki bir önceki ya da bir sonraki eleman ile yer değiştirir. Eğer ÇV'nin en son elemanı ile işlem yapılıyorsa, bir sonraki eleman olarak ÇV'nin ilk elemanı, ÇV'nin ilk elemanı ile işlem yapılıyorsa, bir önceki eleman olarak ÇV'nin son elemanı kabul edilir. Tüm bu işlemler tamamlandıktan sonra, oluşan yeni ÇA'nın yukarıda belirtilen kurallara uygunluğu tekrar kontrol edilir; eğer bir sorun varsa, yeni Ç $A$, ÇV'ler arasindan rastgele oluşturulur.

Yeni ÇA oluşturulduktan sonra, yeni yapılandırma için yük akış analizi koşturulur ve amaç fonksiyonu değeri hesaplanır. Elde edilen bu değer $A H$ içindeki en kötü amaç fonksiyonu değeri ile karşılaştırılır. Eğer bundan daha küçük bir değer elde edilmişse $A H^{\prime}$ 'deki Ç $A$ yerine oluşturulan yeni ÇA yerleştirilir.

Sonra doğaçlama aşamasının en başına dönülür ve tüm işlemler önceden belirlenmiş bir durma koşuluna erişilinceye kadar devam ettirilir. Durma koşulu olarak önceden belirlenen maksimum yineleme sayısı ve çözümdeki değişimlerin durması belirlenebilir. Burada belirtilen çözüm yönteminin, akış şeması aşağıda verilen Şekil 2'de gösterilmektedir.

\section{Benzetimler ve Sonuçlar}

Yukarıda anlatılan yeniden yapılandırma problemi için, 33 dügü̈m noktalı test sisteminde dört farklı durum test edilmiştir. Bunlardan birincisinde sistem yüklerinin referans değerde olduğu varsayılmış, ikincisinde sistemde 4 adet $E A$ şarj istasyonu, 3 adet dizel generatör $(D G)$ ve $250 E A$ olması durumu varsayılmış, üçüncüsünde aynı durumda 500 EA olması varsayılmış ve sonuncusunda $E A$ sayısı 1000 olarak varsayılmıştır.

Benzetimler için Matlab'de armoni araması kodu yazılmış, yük akışı analizi için Matpower [26] programı kullanılmıştır. Testler 33 düğüm noktalı dağıtım sisteminde gerçekleştirilmiştir. İlk durumda sistemdeki referans yük değerleri [7] kullanılmış ve sistemde herhangi bir $E A$ ya da $D G$ olmadığ1 varsayılmıştır. İkinci, üçüncü ve dördüncü test durumlarında Şekil 2'de gösterildiği gibi 4, 10, 11 ve 26 numaralı dügüm noktalarında $E A$ şarj istasyonu olduğu varsayılmış ve 13,14 ve 22 numaralı düğüm noktalarında $300 \mathrm{~kW}$ 'lık $D G$ olduğu varsayılmıştır.

Testlerde $A A B, A H D O$ ve $P A D$ sirasiyla $30,0.8$ ve 0.1 alınmıştır. Maksimum yineleme sayıs olarak 2000 belirlenmiş, son 200 yinelemede en iyi sonucun değişimin belirlenen tolerans değeri olan 0.0001'den küçük olması bir başka durma kriteri olarak göz önüne alınmıştır.

İlk testler referans yük değerleri altında yapılmıştır. En iyi amaç fonksiyonu değeri veren ÇA, $h_{7}, h_{9}, h_{28}, h_{14}$ ve $h_{32}$ olarak belirlenmiştir. Yeniden yapılandırma öncesi aktif güç kayıpları $202.6771 \mathrm{~kW}$ iken yeniden yapılandırılmış durumda $139.9872 \mathrm{~kW}$ değerine düşmüştür. Yeniden yapılandırma öncesi en düşük gerilim genliği $0.9131 \mathrm{pu}$ iken, yeniden yapılandırma öncesi bu değer 0.9413 pu değerine çıkmıştır.

İkinci durumda, en iyi amaç fonksiyonu değerini veren ÇA $h_{7}, h_{9}, h_{28}, h_{12}$ ve $h_{31}$ olarak belirlenmiştir. Yeniden yapılandırma öncesi $217.4138 \mathrm{~kW}$ olan aktif güç kayıpları, yeniden yapılandırma sonrası $137.4057 \mathrm{~kW}$ değerine düşmüsstür. Sistemdeki en düşük gerilim genliği ilk durumda $0.9125 p u$ iken, $0.9405 p u$ değerine çıarılmıştır. 


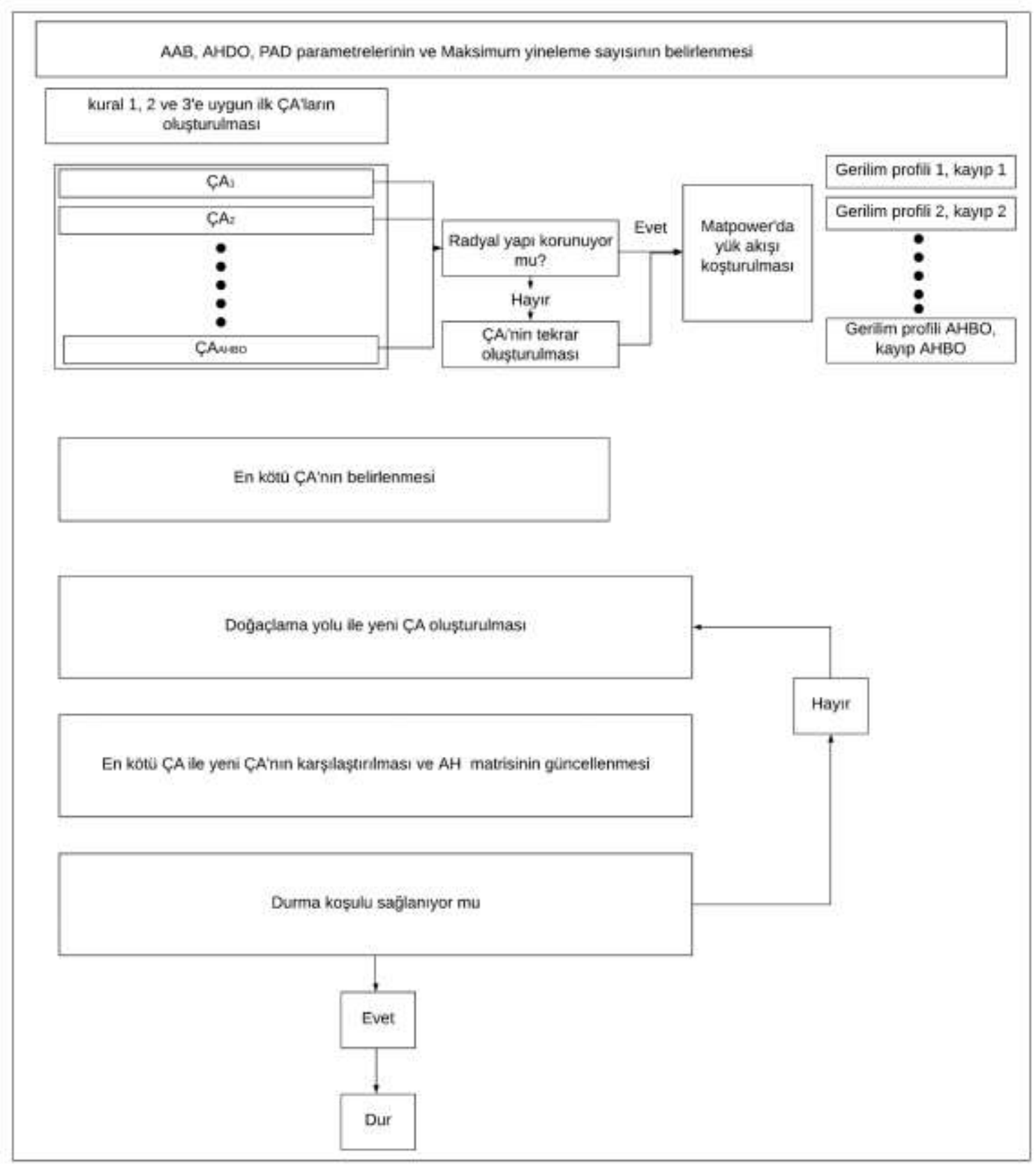

Şekil 2. AAY ile yeniden yapılandırma probleminin çözülmesi için akış şeması

$E A$ sayısının 500'e çıtığı üçüncü test durumunda en iyi ÇA $h_{7}, h_{10}, h_{28}, h_{34}$, ve $h_{32}$ olarak bulunmuştur. Aktif güç kayıpları $332.8879 \mathrm{~kW}$ 'dan $191.4551 \mathrm{~kW}$ değerine düşürülmüştür. Şarj olan $E A$ sayısı bir önceki test durumuna göre daha fazla olduğu için yeniden yapılandırma öncesi sistemdeki en düşük gerilim genliği değeri $0.8959 p u$ değerine düşmüş, bu değer yeniden yapılandırma sonrası $0.9372 p u$ değerine yükseltilmiştir.

Yapılan en son testlerde $E A$ sayıs1 1000'e çıkarılmıştır. Bu durumda en iyi ÇA $h_{7}, h_{10}, h_{28}, h_{12}$ ve $h_{17}$ olarak bulunmuştur. Sistemin yeniden yapılandırma öncesi aktif güç kaybı oldukça fazladır: $719.3970 \mathrm{~kW}$, yeniden yapılandırma sonrası kayıplar $356.9626 \mathrm{~kW}$ 'a indirilmiştir. Gene $E A$ sayısının fazla olmasından ötürü sistem yükü artmış ve en düşük gerilim genliği değeri $0.8408 p u$ olmuştur, yeniden yapılandırma sonrası en düşük gerilim genliği 0.9237 pu değerine yükseltilmiştir. Farklı testler için, yeniden yapılandırma öncesi ve sonrası ortalama gerilim genlikleri Tablo 1'de verilmektedir. 
Tablo 1. Yeniden yapılandırma öncesi ve sonrası sistem ortalama gerilim genlikleri.

\begin{tabular}{|c|c|c|}
\hline$E A$ Sayıs1 & $\begin{array}{c}\text { Yeniden Yapılandırma Öncesi } \\
\text { Ortalama Gerilim Genliği }\end{array}$ & $\begin{array}{c}\text { Yeniden Yapılandırma Sonrası } \\
\text { Ortalama Gerilim Genliği }\end{array}$ \\
\hline 0 & $0.9485 \mathrm{pu}$ & $0.9674 \mathrm{pu}$ \\
\hline 250 & $0.9484 \mathrm{pu}$ & $0.9666 \mathrm{pu}$ \\
\hline 500 & $0.9384 \mathrm{pu}$ & $0.9627 \mathrm{pu}$ \\
\hline 1000 & $0.9060 \mathrm{pu}$ & $0.9494 \mathrm{pu}$ \\
\hline
\end{tabular}

Şekil 3'de ise, tüm testler için, düğüm noktalarındaki gerilim genliği grafikleri yeniden yapılandırma öncesi ve sonrası durumlar için verilmektedir.

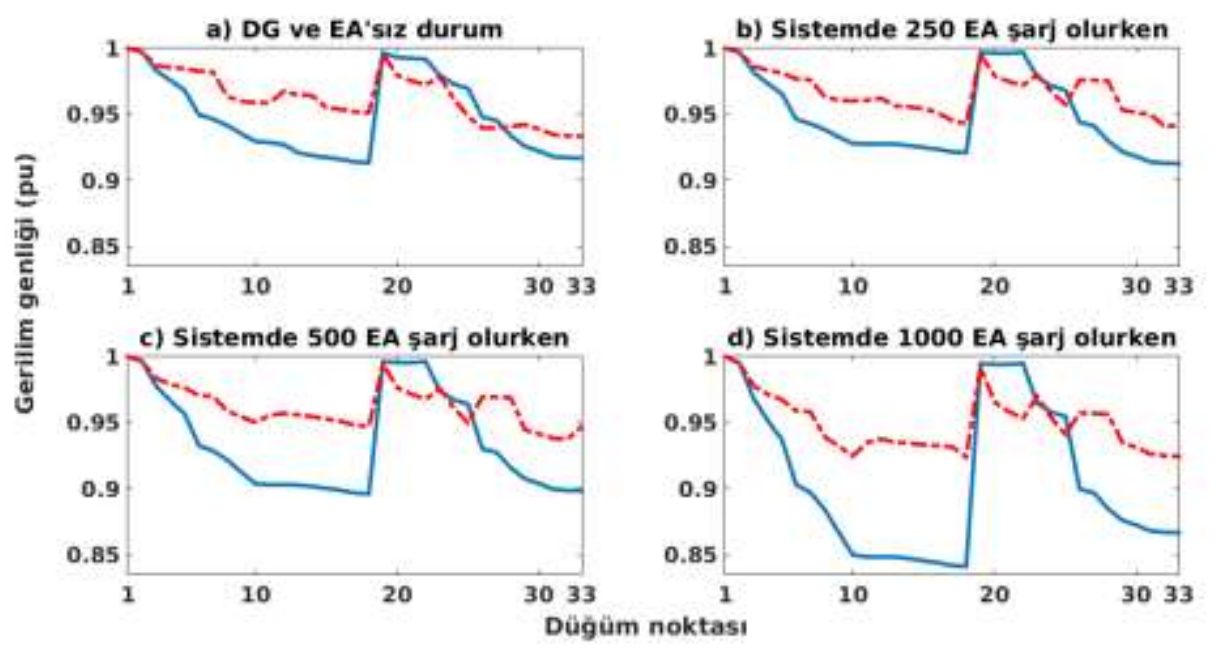

Şekil 3. Farklı EA sayılarına göre yeniden yapılandırma öncesi ve sonrası, düğüm noktaları gerilim genlik değerleri.

Hem Tablo 1'deki verilerden hem de Şekil 4'deki grafiklerden, yeniden yapılandırma sonrası daha iyi gerilim genliği değerleri elde edildiği kolaylıkla gözlenebilir. Ortalama gerilim genliği değerleri iyileştirilmekte, aynı zamanda daha iyi gerilim profili değeri elde edilmektedir.

\section{Sonuçlar ve Gelecek Çalışmalar}

Bu çalışmada elektrik dağıtım sisteminde farklı sayıda $E A$ bulunması durumunda yeniden yapılandırma problemi AAY kullanılarak çözülmüştür. İlk olarak sistemde hiçbir $E A$ bulunmaması durumu göz önüne alınmış, yeniden yapılandırma problemi çözülerek sistem kayıpları azaltılmış ve daha iyi bir gerilim profili elde edilmiştir. Sonra, sistemde 3 adet $D G$ tesis edildiği düşünülerek, sirasıyla 250, 500 ve 1000 $E A$ şarj olurken yeniden yapılandırma problemi çözülmüştür. Yapılan tüm testlerde daha iyi gerilim profilleri elde edilmiş ve toplam sistem kayıpları azaltılmıştır. Elektrik dağıtım sistemlerinde, işletimde, gerilim değerlerinin değişen yük miktarına göre sınır değerlerin altına/üstüne çıkması nedeniyle sıklıkla kontrol işlemleri uygulanması gerektiği için, gelecekteki çalışmalarda, sistem gerilim profilinin, ve kayıplarının 15 dakikalık aralıklarla kontrol edilerek iyileştirmesi planlanmaktadır.

\section{Kaynaklar}

[1] International Energy Agency (IEA) Global EV Outlook 2017. Two Million and Counting. https://www.iae.org.publications/freepublications/publication/GlobalEVOutlook2017.pdf, (Erişim Tarihi: 10.01.2019).

[2] Nissan ABD Web Sayfası 2019. Nissan Leaf Range and Charging. https://www.nissanusa.com/electric-cars/leaf/charging-range/range (Erişim Tarihi: 15.02.2019).

[3] Davis S., Diegel S. 2006. Transportation Energy Data Book, Center for Transportation Analysis Oak Ridge National Laboratory, 410s., Oak Ridge

[4] Ceylan O., Liu G., Tomsovic K. 2018. Coordinated distribution network control of tap changer transformers, capacitors and PV inverters, Electrical Engineering, 100: 1133-1146. 
[5] Ceylan O., Liu G., Tomsovic K. 2014. Distribution system voltage regulation by distributed energy resources. 2014 North American Power Symposium (NAPS), pp 1- 5, 7-9 Eylül, Pullman.

[6] Merlin A., Back H. 1975. Search for a minimal-loss operating spanning tree reconfiguration in an urban power distribution systems. Proceedings of 5th Power System Computation Conference (PSCC), pp 1-18, 1-5 Eylül, Cambridge.

[7] Baran M.E., Wu F.F. 1989. Network reconfiguration in distribution systems for loss reduction and load balancing. IEEE Transactions on Power Delivery, 4 (2): 1401-1407.

[8] Shirmohammadi D., Hong W.H. 1989. Reconfiguration of electric distribution networks for resistive line loss reduction, IEEE Transactions on Power Delivery,4 (1): 1492-1498.

[9] Civanlar S., Grainger J.J., Yin H., Lee S.S.H. 1988. Distribution feeder reconfiguration for loss reduction. IEEE Transactions on Power Delivery, 3 (3): 1217-1223.

[10] Nara K., Shiose A., Kiagawa M., Ishihara T. 1992. Implementation of genetic algorithm for distribution system loss minimum reconfiguration. IEEE Transactions on Power Systems, 7 (3): 1044-1051.

[11] Gupta N, Swarnkar A., Niazi K.R. 2011. Reconfiguration of Distribution Systems for Real Power Loss Minimization Using Adaptive Particle Swarm Optimization. Electric Power Components and Systems, 39 (4): 317-330

[12] Young-Jae J., Jae-Chul K. 2000. Network reconfiguration in radial distribution system using simulated annealing and Tabu search. IEEE Power Engineering Society Winter Meeting, pp. 2329-2333, 23-27 Ocak, Singapur.

[13] Abdelaziz A.Y., Mohamed F.M., Mekhamer S.F., Badr M.A.L. 2010. Distribution system reconfiguration using a modified Tabu Search algorithm. Electric Power Systems Research, 80 (8): 943-953.

[14] Swarnkar A., Gupta N., Niazi K.R. 2011. Adapted ant colony optimization for efficient reconfiguration of balanced and unbalanced distribution systems for loss minimization. Swarm and Evolutionary Computation, 1 (3): 129-137.

[15] Imran, M.A., Kowsalya M. 2014. A new power system reconfiguration scheme for power loss minimization and voltage profile enhancement using fireworks algorithm. International Journal of Electrical Power and Energy Systems, 62: 312-322.

[16] Nguyen T.T., Truong A.V. 2015. Distribution network reconfiguration for power loss minimization and voltage profile improvement using cuckoo search algorithm. International Journal of Electrical Power and Energy Systems, 68: 233-242.

[17] Srinivasa Rao R., Narasimham S.V.L., Ramalinga Raju M., Srinivasa Rao A. 2011. Optimal Network Reconfiguration of Large-Scale Distribution System Using Harmony Search Algorithm. IEEE Transactions on Power Systems, 26 (3): 1080-1088.

[18] Rao SS. 2009. Engineering optimization: theory and practice. Wiley, 903s. New York.

[19] Geem ZW., Kim JH., Loganathan G.V. 2001. A new heuristic optimization algorithm: harmony search. Simulation, 76: 60-68.

[20] Lee K.S, Geem Z.W. 2005. A new meta-heuristic algorithm for continuous engineering optimization: harmony search theory and practice. Computer Methods in Applied Mechanics and Engineering, 194: 3902-3933.

[21] Holland J.H. 1975. Adaptation in Natural and Artificial Systems: An introductory analysis with applications to biology, control and artificial intelligence. University of Michigan Press, 232s. Oxford.

[22] Goldberg D.E. 1989. Genetic Algorithms in Search, Optimisation and Machine Learning. Addison-Wesley, 432s. Reading.

[23] Kennedy J., Eberhart R. 1995. Particle swarm optimization. IEEE international conference on neural networks, pp 1942-1948. 27 Kasim-1 Aralık, Perth.

[24] Dorigo M., Maniezzo V., Colorni A. 1996. Ant System, optimization by a colony of cooperating agents. IEEE Transactions on Systems Man, and Cybernetics, Part B: Cybernetics, 26 (1): 29-41

[25] Ceylan O., Özdemir A., Dağ H. 2016. Heuristic methods for postoutage voltage magnitude calculations. Turkish Journal of Electrical Engineering and Computer Sciences, 24: 105-120.

[26] Zimmerman R.D., Murillo-Sánchez C.E., Thomas R.J. 2011. MATPOWER: Steady-state operations, planning, and analysis tools for power systems research and education. IEEE Transactions on Power Systems, 26 (1): 12-19. 